\title{
2016 AECT International Convention Summary
}

\author{
Donovan R. Walling ${ }^{1}$
}

Published online: 15 December 2016

(C) Association for Educational Communications \& Technology 2016

Las Vegas is known for its wow factor, but participants did not have to step outside the convention hotel to be wowed at the 2016 AECT International Convention. For one thing, there were more than 1,000 participants-educators, practitioners, researchers, scholars, and students from around the world. That made networking dynamic and international over the entire convention, from October 17 to 21 . Then, of course, there were the sessions, a mix of workshops, roundtables, poster sessions, keynotes, and so on-more than 400 opportunities to "learn from Las Vegas," as the convention theme announced.

It is impossible to summarize a convention of this scope in a few words. So here some highlights, focusing mainly on the three keynote presentations and the presidential sessions.

On the opening day, the first general session, which included the formal passing of the presidential gavel, brought the world-famous Cirque du Soleil up close and personal to AECT convention participants in a Spark Session called, "Technology and Training at Cirque du Soleil." The challenge on the founding of Cirque du Soleil 30-plus years ago was to reinvent the circus concept, basing it on a street performance tradition. This meant not using animals and focusing on human performance, often technology-mediated with increasing sophistication over the years to "deliver the unexpected." Cirque grew from a "band of merry misfits roaming the French Canadian countryside" to a multimillion dollar industry with multiple shows being mounted around the world. A panel of Cirque du Soleil executives - a stage manager, a company manager, and a general stage manager, each from a

Donovan R. Walling

drwalling@gmail.com

1 Bloomington, IN, USA different show—-talked about teaching and learning and technology, which transform world-class athletes, usually with a background in gymnastics, into artists who perform daily week after week. The session offered convention participants an opportunity to learn about technology, instructional design, teaching, and learning translated from academe to the world of international theater.

The second general session featured Philip Yenawine, cofounder of Visual Understanding in Education, a nonprofit research organization, on "Technology and Inquiry: Using Questions to Provoke Discussions." According to Yenawine, "Schools must empower and equip teachers to enable students to learn how to learn." This became the anchor for his presentation, much of which revolved around visual arts as references and starting points for inquiry. Paintings, for example, usually provide a balance of the familiar and the intriguing, which facilitates engagement. Often a key question is, "What's going on here?" Engagement in making meaning amplifies learning and retention. Individuals have the ability to learn at a high level depending on how they are taught. Teachers can amplify ability and make learning authentic and experiential, and thus lasting. Yenawine's keynote, punctuated with multiple visuals and audience interactions, exemplified the convention focus on creativity.

The third general session was keynoted by Barry Kudrowitz, an assistant professor of product design at the University of Minnesota, whose topic was "Play and Creativity in the Classroom." Coming from a highly diverse, highly creative background - everything from designing toys to earning a Ph.D. from MIT in mechanical engineeringKudrowitz's own research is in humor and creativity. He led off with an activity, asking participants to write down in $3 \mathrm{mi}-$ nutes as many uses for a paperclip as possible. Afterward he explained that the activity was actually a test of divergent thinking, called the Alternative Uses Test. "The best way to 
have a good idea is to have a lot of ideas," according to Linus Pauling, Kudrowitz reminded participants. The issue is that creativity is declining among children, and that is where play can provide vehicles for reversing the decline. Play is how children learn in every way. According to Kudrowitz, play is a quality of mind, not an activity. Play is captivating, intrinsically motivated, process focused, and involves some level of pretense. Participants discovered much in this session to think about—and had fun doing it.

Philip Yenawine and Barry Kudrowitz also provided a followup conversation on creativity as a presidential session after the third general session.

The presidential sessions ranged broadly. M. David Merrill (retired from Utah State University) presented "The Next to the Last Lecture: A 50+ Year Search for Effective, Efficient, and Engaging Instruction.” Always engaging himself, Merrill reflected on his long - and by no means finished - career, providing what he termed "back stories" to his work. For example, he revealed that his father was an artist, that he had been a missionary for the Mormon church, that he had multiple majors related to educational psychology, that he invented a number system using an oar and a rubber boot, and that he did his dissertation on computer-based instruction in the 1960s, when computers were in their infancy. He recalled hearing B.F. Skinner say, "All I've ever tried to do was make as few assumptions as possible," a philosophy that influenced his thinking. And he also talked about how his lifelong correspondence with Robert Gagné developed. Participants got a personalized history of learning theories and computer-based instruction. The session was full of fun and insight.

"Sparking the Creative Process: A Mid-Conference Creative Break," was designed as an interactive, social gathering to boost creative potential. The session began with a 12minute free-writing time based on an "object" to get the creative juices flowing. The participants then shared their efforts in small groups. A prompt based on an imaginary character provided the basis for a second writing activity, again followed by time to share with other participants. The session culminated in broader sharing by representatives of the small groups. Participants seemed to agree that the session was, as billed, a creative break that would help them focus in new ways as they resumed their schedule of more academically oriented sessions.

Harvard University's Chris Dede presented "Big Data in Education: Implications for Design." He organized his presentation around data-intensive research experiences and how instructional designers need to think about big data. "Big data" is a relative term involving new ways to understand data. "Big" is characterized by volume, velocity, variety, veracity. Educators are challenged by all four Vs, according to Dede. A key resource he mentioned is a 2015 report, which Dede led in developing, titled Data-Intensive Research in Education: Current Work and Next Steps, which can be downloaded from Computing Research Association at cra.org. The session provided guidance on designing instruction for data-based teaching and learning.

"Designing for Human Learning in the Anthropocene" brought together a diverse international panel of scholars led by Jan Visser (Learning Development Institute) to discuss how thinking about teaching and learning needs to change in order to meet the challenges of the current era, identified by a growing body of literature as the Anthropocene, in which "business as usual" no longer suffices. The term Anthropocene refers to a proposed name for the current epoch, beginning in the 18th century, in which humans are the most significant influence on the natural state of the planet. The panel delved into six questions surrounding the meaning of design, the nature of human learning, habits of thinking, hidden assumptions in the "mantra" of instructional design, research traditions, and technology as "design for instrumental action." In addition to the comments from the panelists, the audience was drawn into a larger discussion.

J. Michael Spector (University of North Texas) led a distinguished panel for "Creativity in Learning and Instruction: Inquiry Learning." Their focus was referenced to the online Major Reference Work, which is an AECT/Springer collaboration, and a forthcoming special edition of a journal. Panelists honed in on creative and critical thinking, particularly how creative thinking can be developed. Spector talked about the importance of helping students learn how to ask questions and some critical factors in doing so. Miguel Nussbaum (Pontificia Universidad Catolica de Chile) addressed students' individualized learning and how teacher mediation can develop students' self-directed learning and the role of critical thinking in creativity. Brad Hokanson (University of Minnesota) spoke about training, not teaching, students to be creative, specifically choosing the unfamiliar over the familiar-i.e., divergent thinking. M. David Merrill served as the critical discussant, and an audience discussion followed.

"Human Learning and Machine Learning: A Partnership for Creative Design" was presented by Thomas C. Reeves (University of Georgia). He took up the idea that the future of learning is one of human versus machine. But there are skills, many revolving around aspects of creativity, that give humans the edge when it comes to the future of instructional design as a human career. Ideation, pattern recognition, and complex communication are key skills for instructional designers - and good designers are in short supply, making instructional design a growth industry. But...what about "automated" instructional design involving computers? There was a surge in this thinking in the 1990s; however, more recent work has questioned the limitations of this direction, absent high human interactivity. A synthesis seems to be more likely.

Richard Ingram (James Madison University) presented "Implementing Burke Connection Mapping for Creative Insight into Content and Design," based on the work of James Burke. The purpose of such mapping is to discern 
connections that result in change or discovery. Learning connections are neural connections that resemble the Burke mapping. Often the benefits of such thinking are divergent and creative - thinking that goes beyond the traditional silos of disciplines, for example. This session was designed to help participants develop effective techniques for implementing such mapping and provided a hands-on activity to this end. It also introduced the James Burke Connections App concept and the coming campaign to develop the app.

These highlights barely scratch the surface. Each AECT division offered a strand of multiple sessions and other learning opportunities, from formal dinners and meetings to informal lunches and conversations over cocktails. And there was plenty of fun, too. How about tango dancing? No experience needed. The annual "Tech Travesties" was greeted with giggles and guffaws. The Emerging Technologies Showcase displayed a wide array of technologies being used in innovative ways by AECT members. And "Paralleling Women as Presidents of AECT with Changes in the U.S. Laws and Social Norms" offered a unique association-focused historical perspective. All in all, the 2016 AECT International Convention served up something - many things - for everyone. AECT members who missed this event, will find keynotes and presidential sessions archived on the AECT Vimeo website. Moreover, AECT members and other professionals will find not a replica but many new opportunities this coming November when the 2017 AECT International Convention opens in Jacksonville, Florida, with the theme, "Leading Learning for Change." Make plans now to attend. 